\title{
TTR
}

Traduction, terminologie, re?daction

\section{In Memoriam André Lefevere}

\section{José Lambert et Théo Hermans}

Volume 9, numéro 1, 1er semestre 1996

Le festin de Babel

Babel's Feast

URI : https://id.erudit.org/iderudit/037235ar

DOI : https://doi.org/10.7202/037235ar

Aller au sommaire du numéro

Éditeur(s)

Association canadienne de traductologie

ISSN

0835-8443 (imprimé)

1708-2188 (numérique)

Découvrir la revue

Citer ce document

Lambert, J. \& Hermans, T. (1996). In Memoriam André Lefevere. TTR, 9(1), 7-8.

https://doi.org/10.7202/037235ar d'utilisation que vous pouvez consulter en ligne.

https://apropos.erudit.org/fr/usagers/politique-dutilisation/ 


\section{IN MEMORIAM ANDRÉ LEFEVERE}

Victime d'une crise totalement inattendue, André Lefevere a quitté ce monde le 27 mars 1996, à Austin (Texas), à l'âge de 50 ans. C'est un des profits les plus brillants de notre discipline qui disparait ainsi, alors que rien ne donnait l'impression que la vitalité ou la combativité de ses vingt ans l'avaient quitté. Mort sur son champ de bataille, comme il l'aurait peut-être souhaité, sans doute même avec le sourire. Fauché en quelques heures, apparemment en douceur, d'autant plus cruellement pour ceux qui lui étaient chers.

Né dans le plat pays des Flandres chanté par Jacques Brel, Lefevere avait fait ses études de philologie germanique à Gand. Le grand air l'attirait, et un don exceptionnel des langues ainsi que la curiosité des cultures le poussaient à conquérir le monde. C'est à Hong Kong, et non en Flandres, qu'il entama sa carrière en littérature comparée, c'est à Essex qu'il défendit sa thèse sur les traductions de Catulle (Seven Strategies, sorti en 1975 , et c'est à travers le monde entier qu'il milita en faveur d'une littérature comparée nouvelle où la question des langues et des traductions aurait sa place, au point de se faire traiter sans perdre le sourire, avec quelques confrères, de «Bouvard et Pécuchet de la littérature comparée». De 1973 à 1984, il enseignait à l'UIA d'Anvers: retour au pays, mais portes ouvertes. Le colloque de Leuven en 1976 (Literature and Translation, publié en 1978) le mit en contact avec le groupe israélo-belgo-hollandais (Even-Zohar, Toury, van der Broek, Lambert, Holmes) et avec Susan Bassnett, ce qui donna lieu à une série de colloques et publications nouveau style. Entre temps, il avait étalé sa polyvalence de théoricien dans des livres de théorie littéraire (The Growth of Literary Knowledge, 1977), ses connaissances historiques et culturelles dans ses explorations de 
l'histoire des traductions. Son flegme et son talent de conférencier lui valurent un rôle de vedette dans un chapelet de grands congrès, aux côtés et souvent contre les grands du monde entier. En 1984, il s'établit à Austin (Texas) pour y enseigner, loin des Flandres, la littérature néerlandaise, à laquelle ses activités de traducteur lui avaient permis de rester fidele. C'est à partir du Texas qu'il a ensuite milité en faveur d'une conception multiculturelle des sociétés où la traduction occupait une place centrale. Les États-Unis et le monde anglo-saxon lui doivent pour une bonne part d'avoir découvert la question des traductions. C'est à ce moment qu'il a lancé avec Susan Bassnett, à partir de l'Angleterre, sa collection de livres sur la traduction qui fut un des événements des années 1980. En 1992, en une seule année, il sortit, outre sa portion habituelle d'articles de haute volée, trois livres de niveau international. En 1995 il occupa la chaire CETRA à Leuven - autre retour au pays natal -, où il exhibait sa jeunesse mentale parmi les jeunes de plusieurs continents. Hélas! Ce ne sera plus possible. André, Homo Viator, adieu.

José Lambert et Théo Hermans 